\title{
Prediction of Hydrogen Solubility in Heavy Hydrocarbons over a Range of Temperatures and Pressures using Molecular Dynamics Simulations
}

\author{
Huajun Yuan ${ }^{\dagger}$, Christopher Gosling ${ }^{\star}$, Peter Kokayeff* and Sohail Murad* ${ }^{\dagger}$ \\ Department of Chemical Engineering, University of Illinois at Chicago, 810 South Clinton
}

Street, Chicago, IL 60607, and UOP LLC, 25 E Algonquin Rd, Des Plaines, IL 60016

\begin{abstract}
Using the method of molecular dynamics (MD), we have estimated the solubility of hydrogen in heavy hydrocarbons for a range of temperatures and pressures. Heavy hydrocarbon systems are known to be challenging not only for experimental measurements but also for reliable estimations using traditional equations of state (EOS). The simulation system used was designed with semi-permeable membranes to mimic actual experimental studies of gas solubility. Binary interaction parameters between the solute gas and the solvent (heavy hydrocarbons) components were adjusted when necessary to improve agreement with experimental results and then used in subsequent multi-component studies. Temperature and pressure ranges studied included higher temperatures and pressures which are especially difficult to investigate experimentally. Simulation results were finally used to adjust the binary interaction parameters (BIP) in simulation packages (e.g. Aspen) to enable quick and reliable predictions.
\end{abstract}

\footnotetext{
*Address correspondence to this author. E-mail: murad@ uic.edu. Phone: (312)-996-5593. $\uparrow$ University of Illinois at Chicago

+ UOP LLC
} 


\section{Introduction}

The solubility of gases in liquids can range over many orders of magnitude [1]. While the fundamental principles of thermodynamics governing solubility are quite well understood, it is still not possible, however, to make accurate predictions of solubility for industrially important systems using molecular thermodynamics only[1]. Industrial projects are at the same time driving the need for increasingly complex and faster measurements with smaller samples under difficult conditions. The need for better models and data, for pure component as well as mixture properties, for industrial purposes has been recently described [2-3]. It has been pointed out in particular, the need to properly account for the effect of the underlying fundamental interactions at the molecular level on the macroscopic behavior of fluids. The increasing capability and complexity of software for process simulation applications also motivates the need for development and validation of better physical property models. This study addresses such a need. At the molecular level, different computer simulation techniques such as molecular dynamics (MD) [4], Monte Carlo methods [5], MD combined with electro density-function theory [6-7] have been developed over the past few decades.

Molecular-based studies of fluids can play an important role in meeting the physical property-related needs of the chemical industry. For example, the solubility of gases in liquids is an important problem in phase equilibrium [8-9]. It is more complicated than conventional vapor-liquid equilibrium, since in many cases the solubility of gases in liquids can be very low (mole fractions of the order of $10^{-5}$ ) at standard pressures, making accurate experimental measurements or theoretical predictions exceedingly difficult [10]. 
The importance of gas solubility is also demonstrated by the numerous data compilations available [11]. In particular, hydrogen solubility is needed for the modeling of hydrogenation processes, where such data is extremely crucial but traditional equation of state methods do not provide accurate enough estimates. The solubility data is important to determine the optimal amount of hydrogen needed in the hydrogenation process and to improve plant safety. Excess hydrogen can result in energy being wasted and is also a potential safety hazard if too much is added during hydrogenation.

Due to the complexity of heavy hydrocarbons (mixtures of various heavy components), experiments are particularly difficult to perform. In addition, hazards associated with extreme conditions in many industrial processes (high temperatures and/or high pressures), make extensive experimentation not an attractive option. Modeling is therefore an ideal and safe alternative (computers seldom blow up!), provided that the methods and parameters of molecular level modeling can be validated experimentally. Ungerer et al have recently reported molecular simulation studies to predict thermodynamics properties of hydrocarbons [12] and the solubility of hydrogen sulfide in hydrocarbons using the Anisotropic United Atom (AUA) intermolecular potential [13]. Traditional equations of state (EOS) can often provide reliable results at low temperature and pressure, but the errors become significant when the temperature and pressure are increased. By contrast when using molecular simulation, the temperature should have only a small effect on cross interaction parameters (the most important parameter for low solubility systems), which leads to more reliable prediction at extreme conditions [8-9]. In this work, we will use a specially configured simulation system to predict the solubility of 
hydrogen. The results obtained will then be compared with both available experimental and EOS results.

The goal of this work is to design molecular simulation systems which can closely mimic real experiments and also allow us to estimate gas solubility using more simple methodologies. Here we present the results of computer simulations for solubility estimations of hydrogen in heavy hydrocarbons. The results from these simulations will allow us to better understand the interactions between the solute gases and solvents, and thus allow more extensive use of computer modeling methods in the chemical industry for reliable property estimations. We have previously used similar methods developed in our research group successfully to study the solubility of light gases in n-alkanes, cyclo-alkanes, polar fluids, and benzene [8-10, 14].

\section{Potential Models}

The first and most important element in an MD simulation is the definition of an intermolecular potential function by which the particles will interact with each other. The potentials may be defined at different levels of physical accuracy, but are usually based on molecular mechanics and are able to reproduce structural properties and conformational changes.

A variety of potential functions have been used to fit the structural data and other properties of liquids. The most useful form for our simulations is the site-site interaction potential of the form: 


$$
u_{i j}=4 \varepsilon_{i j}\left[\left(\frac{r_{i j}}{\sigma_{i j}}\right)^{-12}-\left(\frac{r_{i j}}{\sigma_{i j}}\right)^{-6}\right]
$$

Where $r_{i j}$ is the scalar distance between site $\mathrm{i}$ and site $\mathrm{j}$, and $\varepsilon_{i j}$ and $\sigma_{i j}$ are the LJ interaction parameters. These interactions are then summed over all active sites.

For complex molecules we must also consider the intramolecular interactions. The most important intramolecular interactions include bond (length and angle) vibrations, and tortional motion which can be modeled as:

$$
u_{\text {int ramolecular }}=\frac{1}{2} \sum_{\text {bonds }} k_{i j}^{r}\left(r_{i j}-r_{e q}\right)^{2}+\frac{1}{2} \sum_{\text {angles }} k_{i j k}^{\theta}\left(\theta_{i j k}-\theta_{e q}\right)^{2}+\frac{1}{2} \sum_{\text {torsions }} \sum_{m} k_{i j k l}^{\phi, m}\left(1+\cos \left(m \phi_{i j k l}-\gamma_{m}\right)\right)
$$

The potential parameters used for hydrocarbons in the present study are the TraPPE united atom model parameters from the Siepmann group which are widely used for organic liquids [15-19]. For hydrogen we used parameters reported in reference [20]. These are listed in Table 1 below.

Table 1 Parameters used for $\mathrm{H}_{2}$ and hydrocarbon molecules:

\begin{tabular}{|c|c|c|c|}
\hline Pseudo-atom & $\varepsilon_{\mathrm{ij}} / K_{\mathrm{B}}(\mathrm{K})$ & $\sigma_{\mathrm{ijj}} / \AA$ & Reference \\
\hline $\mathrm{CH}_{3}\left(\mathrm{sp}^{3}\right.$-alkyl $)$ & 98.0 & 3.75 & {$[21]$} \\
\hline $\mathrm{CH}_{2}\left(\mathrm{sp}^{3}\right.$-alkyl $)$ & 46.0 & 3.95 & {$[21]$} \\
\hline $\mathrm{CH}\left(\mathrm{sp}^{3}\right.$-alkyl $)$ & 10.0 & 4.68 & {$[15]$} \\
\hline $\mathrm{CH}_{2}\left(\mathrm{sp}^{3}\right.$-cyclic $)$ & 3.93 & 52.3 & {$[21]$} \\
\hline $\mathrm{CH}\left(\mathrm{sp}^{2}\right.$-aromatic) & 50.5 & 3.695 & {$[21]$} \\
\hline $\mathrm{C}\left(\mathrm{sp}^{2}\right.$-aromatic) & 21.0 & 3.88 & {$[20]$} \\
\hline $\mathrm{H}_{2}$ & 0.2759 & 2.97 & \\
\hline
\end{tabular}




\begin{tabular}{|c|c|c|c|c|c|}
\hline Bond Length & \multicolumn{2}{|c|}{$\mathrm{R}_{\mathrm{o}} / \AA$} & & & \\
\hline $\mathrm{CH}_{\mathrm{x}}-\mathrm{CH}_{\mathrm{y}}$ (alkyl) & \multicolumn{2}{|c|}{1.54} & \multicolumn{3}{|c|}{ [15] } \\
\hline CH-CH (aromatic) & \multicolumn{2}{|c|}{1.40} & \multicolumn{3}{|c|}{ [21] } \\
\hline Bend & $\theta_{\mathrm{o}} /$ degree & $\mathrm{K}_{\theta} / K_{\mathrm{B}}(\mathrm{K})$ & & & \\
\hline $\mathrm{CH}_{\mathrm{x}}-\mathrm{CH}_{2}-\mathrm{CH}_{\mathrm{y}}$ & 114 & 62500 & \multicolumn{3}{|c|}{ [15] } \\
\hline $\mathrm{CH}_{\mathrm{x}}-\mathrm{CH}\left(\mathrm{CH}_{3}\right)-\mathrm{CH}_{\mathrm{y}}$ & 112 & 62500 & \multicolumn{3}{|c|}{ [15] } \\
\hline Torsion & $\mathrm{C}_{0} / K_{\mathrm{B}}(\mathrm{K})$ & $\mathrm{C}_{1} / K_{\mathrm{B}}(\mathrm{K})$ & $\mathrm{C}_{2} / K_{\mathrm{B}}(\mathrm{K})$ & $\mathrm{C}_{3} / K_{\mathrm{B}}(\mathrm{K})$ & \\
\hline $\mathrm{CH}_{\mathrm{x}}-\mathrm{CH}_{2}-\mathrm{CH}_{2}-\mathrm{CH}_{\mathrm{y}}$ & 0 & 335.03 & -68.19 & 791.32 & [15] \\
\hline $\mathrm{CH}_{\mathrm{x}}-\mathrm{CH}_{2}-\mathrm{CH}\left(\mathrm{CH}_{3}\right)-\mathrm{CH}_{\mathrm{y}}$ & -251.06 & 428.73 & -111.85 & 441.27 & [15] \\
\hline
\end{tabular}

The Lorentz-Berthelot mixing rule was used for unlike interactions [23].

$$
\begin{aligned}
\sigma_{i j} & =\frac{\eta}{2}\left(\sigma_{i i}+\sigma_{j j}\right) \\
\varepsilon_{i j} & =\xi \sqrt{\varepsilon_{i i} \varepsilon_{i j}}
\end{aligned}
$$

We note that changing the interaction coefficients $\eta$ and $\xi$ significantly changes the solubility of $\mathrm{H}_{2}$ in the solvent.

\section{Simulation Details}

\subsection{Simulation of Heavy Hydrocarbons}

The composition of heavy hydrocarbons is rather complicated, but in general consists of normal paraffins, iso-paraffins, mononaphthenes, 2+ ring naphthenes, mono aromatics, diaromatics and multiple ring aromatics. The molecular structures/formulas of the various components are generally not known although the carbon numbers of each category can be estimated from two dimensional GC results. Typical heavy hydrocarbons show the average carbon numbers of each category to be about 30 (within the range 11 to 48 ) [24, 25]. To 
avoid the need to simulate a large number of complex molecules, we chose to represent each functional group described above by one representative molecule. The parameters for such a representative molecule were carefully chosen to realistically represent the structure and composition of the entire group. The number of representative molecules in the mixture can be adjusted according to the composition of the mixture. We chose two strategies to represent each group, which for convenience we will refer to as the "Representative Molecules Approach", and "Pseudo Molecules Approach". These are described below.

\subsubsection{Representative Molecules Approach}

The basic strategy here is the selection of six representative molecules, one for each group in a typical heavy hydrocarbon: n-paraffins, isoparaffins (represented both together by squalane); mononaphthenes (represented by methylcyclohexane derivatives); $2+$ ring naphthenes (represent by dicyclohexylethane derivatives); monoaromatics (represented by benzene derivatives); diaromatics (represent by naphthalene derivatives); 4+ ring aromatics (represent by chrysene derivatives). These components were chosen based on the known compositions of heavy oils and vacuum gas oils [24, 25], and are shown in Fig.1 below: 


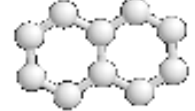

Naphthalene

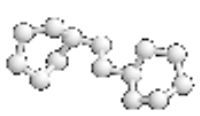

Dicyclohexylethane

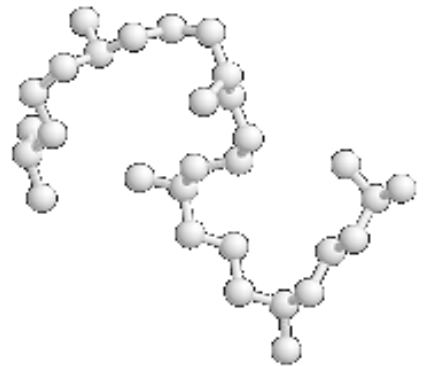

Squalane
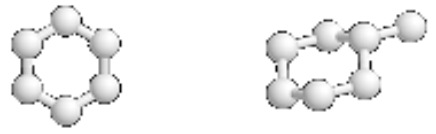

Benzene Methylcyclohexane

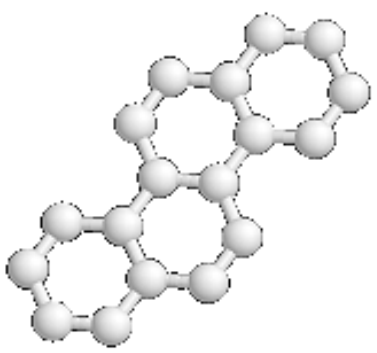

Chrysene

Figure 1 : Molecular structures of the representative hydrocarbon components investigated

\subsubsection{Pseudo Molecules Approach}

Since the average carbon number of heavy hydrocarbons is in the C30 range [24, 25], we chose representative molecules with the molecular weights also in this desired range as opposed to the previous approach where we ensured the weight fraction of each functional group only to be correct. Besides squalane, our choices for the various heavy hydrocarbons are shown in Figure 2. 


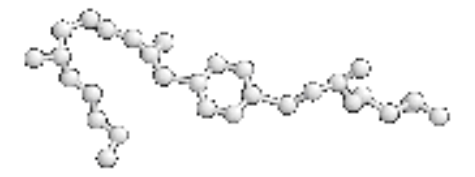

C30 derived from benzene

(mono-aromatics)

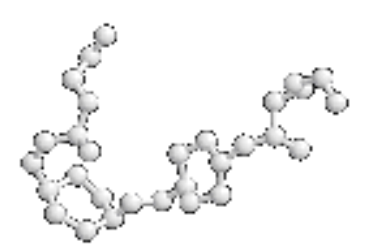

C30 derived from dicyclohexylethane (2+ ring naphthenes)

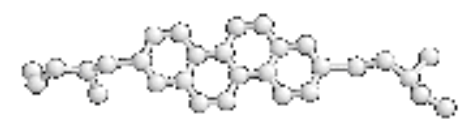

C30 derived from chrysene (4+ ring aromatics)

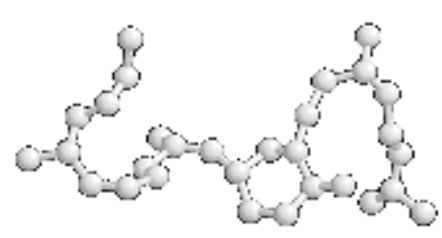

C30 derived from methylcyclohexane (mono-naphthenes)

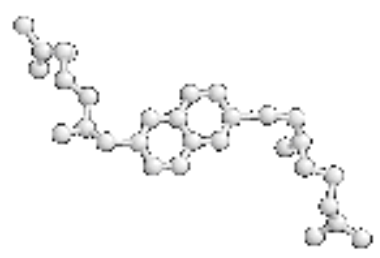

C30 derived from naphthalene

(di-aromatics)

Figure 2: Molecular structure of built pseudo components investigated

Once these representative molecules have been selected for each category, the heavy hydrocarbons can be represented as a mixture of these components based on the compositions of interest. Structures of these components were estimated using an energy minimization method [26].

\subsection{Simulation System}

Our simulation consisted of a total of 480 molecules, with the amount of each component fixed to represent a typical heavy oil mixture. Table 2 shows one such typical mixture 
investigated in this study using the "Representative Molecules Approach". This methodology is similar to that used by Ungerer et al [13] in their study of hydrocarbon mixtures.

Table 2 A typical simulation system for heavy hydrocarbons

\begin{tabular}{|c|c|c|c|c|}
\hline Catalogy & $\begin{array}{c}\text { Represent Component or C30 } \\
\text { pseudo molecules }\end{array}$ & Mol\% & \# molecules & MW \\
\hline Paraffins & Squalane & 12.5 & 60 & 422.82 \\
\hline Mononaphthene & Methylcyclohexane & 6.458 & 32 & 98.21 \\
\hline 2+ ring naphthenes & Dicyclohexylethane & 5.417 & 26 & 194.356 \\
\hline Monoaromatics & Benzene & 7.08 & 34 & 78.118 \\
\hline Diaromatics & Naphthalene & 34.17 & 164 & 128.17 \\
\hline 4+ ring aromatics & Chrysene & 34.38 & 164 & 228.3 \\
\hline Total & & 100 & 480 & \\
\hline
\end{tabular}

The simulation system used for this study is shown in the Figure 3, using squalane as an example. The system consists of two solution sections (containing both hydrogen and solvent molecules) connected to each other via periodic boundary conditions and a gas section in the middle separated by a semi-permeable membrane (permeable to $\mathrm{H}_{2}$ molecules only).

The molecules in the simulation system were initially in an FCC configuration, we annealed the system at a relatively high temperature to ensure equilibration of the solvent molecules. Following such an equilibration, hydrogen molecules were introduced into the 
system. During the annealing process we also ensured that the squalane had a uniform density profile and there were no static voids in the liquid phase.
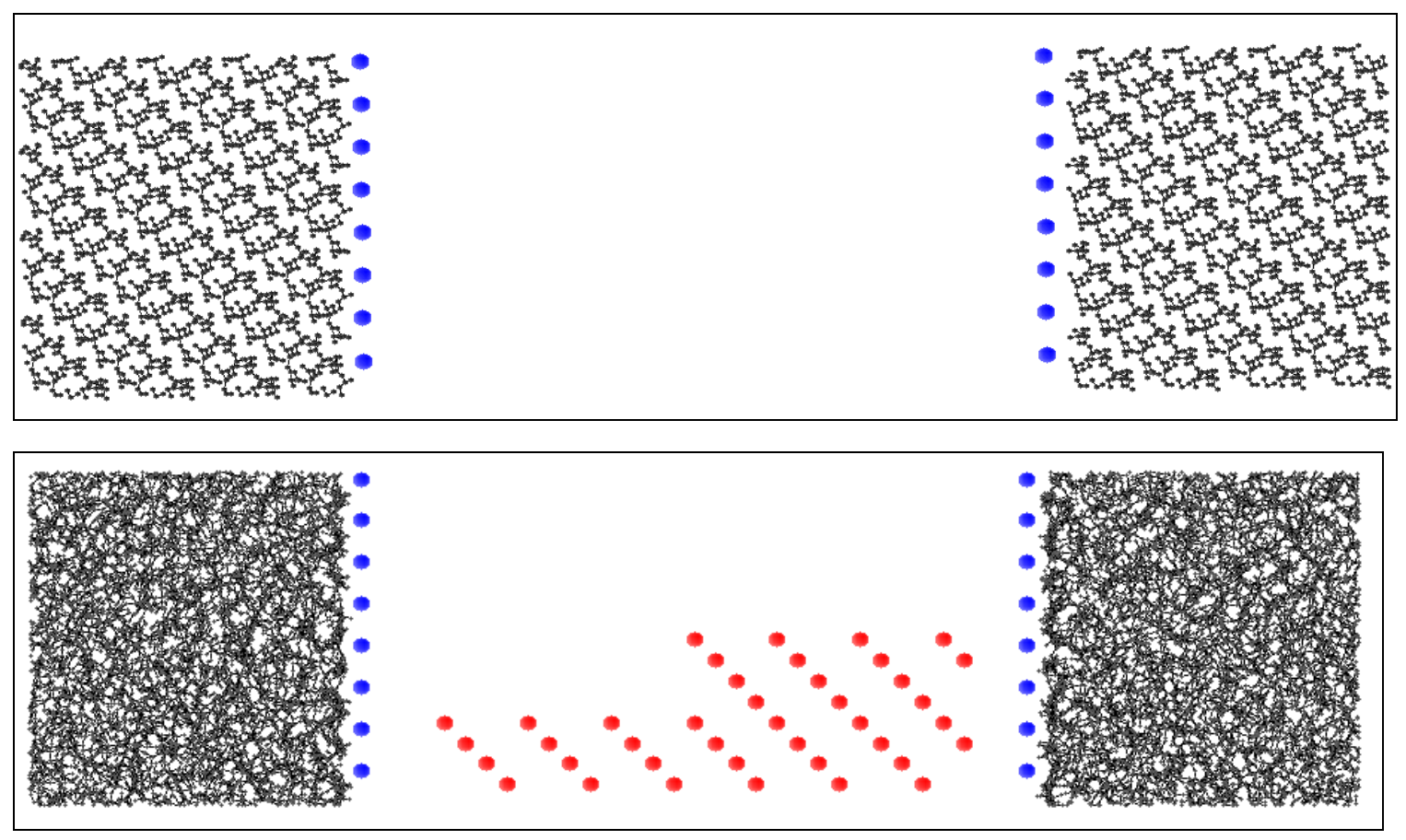

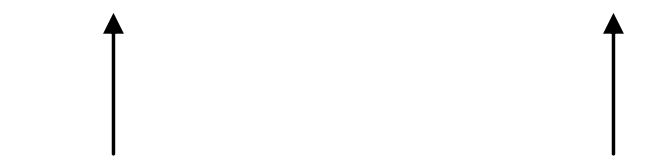

Solution Section
Gas Section

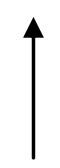

Solution Section

Figure 3 Typical simulation system configuration: initial setup (top) and system with hydrogen introduced (bottom), 480 Squalane +128 Membrane $+40 \mathrm{H}_{2}$ molecules

We carried out simulations for a range of pressures. To vary the initial gas pressure we adjusted the initial number of $\mathrm{H}_{2}$ molecules in the gas section: For example, $40 \mathrm{H}_{2}$ molecules in the gas compartment only lead to low pressures. The number of $\mathrm{H}_{2}$ molecules in the gas section can then be increased to study higher pressures. In our studies we included $40 \sim 160 \mathrm{H}_{2}$ molecules. Density profiles (distributions) in the simulation system 
were then used to obtain Henry's constants for the desired temperature and pressure. This was only done after ensuring that equilibrium has been reached, and density profiles were uniform away from the membrane regions.

In our molecular dynamics simulations, we used a Verlet velocity algorithm which is widely used [27], with a 2 fs time step. All the simulations were performed using the LAMMPS simulation package [26]. Further details of the method are available elsewhere [8].

\subsection{Henry's Constant Calculation}

The Henry's constant from the simulations was obtained from the standard equation [10]

$$
H_{12}\left(T, P_{2}^{s a t}\right)=\lim _{x_{1} \rightarrow 0}\left\{\frac{P^{(V)} \phi_{1}}{\gamma_{1}^{*} x_{1} \exp \left\{\left(P^{(L)}-P_{2}^{s a t}\right) \bar{V}_{1}^{\infty} / R T\right\}}\right\}
$$

Subscript 1 refers to the solute $\left(\mathrm{H}_{2}\right)$ molecules, while 2 to the solvent molecules. In this equation, $\mathrm{x}_{1}$ represents the mole fraction of $\mathrm{H}_{2}$ in the solution, obtainable directly from the density profiles. We also included contributions from the gas phase non-ideality $\left(\phi_{1}\right)$. The pressure $\left(\mathrm{P}_{1}\right)$ of the $\mathrm{H}_{2}$ gas phase is estimated from the density $(\rho)$ of the gas phase and the second virial coefficient B using the equation [29]

$$
\mathrm{P}=(1+\mathrm{B} \rho) \rho \mathrm{RT}
$$

The vapor phase fugacity coefficients $(\phi)$ can similarly be obtained using [10]

$$
\ln \phi=2 \rho B-\ln (P / \rho R T)
$$


Equation (5) also includes contributions from solvent phase non idealities. The pressure in the solvent compartment $\left(P_{2}\right)$ can be calculated from the average force on the membranes separating the two compartments in the simulation box, which represents the pressure difference between the two compartments. $\bar{V}_{1}^{\infty}$ (the partial molar volume of the solute at infinite dilution) is available from experimental measurements or can calculated directly by carrying out a few extra simulations (at least one ). These additional simulations should be at the same temperature but different pressures. Assuming $\bar{V}_{1}^{\infty}$ and $\gamma_{1}{ }^{*}$ are independent of pressure, ${ }^{\infty}$ can then be calculated using equation (5). In our studies we used a value of $39.82 \mathrm{~cm}^{3} / \mathrm{mol}$ from reference [28] for hydrogen partial molar volume in olive oil (this value varies very little for most heavy hydrocarbons) at infinite dilution. Using this value the largest Poynting correction is only 1.046 at $353 \mathrm{~K}$. This should not be surprising since most hydrogen molecules just fill the voids in the liquid structure of heavy hydrocarbons. This leads to very small increases in the liquid phase volume when hydrogen dissolves in the heavy hydrocarbons, and thus very small partial molar volumes. Finally, since we are using a semi-permeable membrane (which only allows hydrogen permeation) there are no hydrocarbons present in the gas (hydrogen) phase. This finally leads to a simplified relationship (if one ignores the relatively minor Poynting correction) for Henry's constant when $x \rightarrow 0$ as :

$$
H_{12}=\lim _{x_{1} \rightarrow 0}\left\{\frac{P_{1} \phi_{1}}{x_{1}}\right\}
$$




\subsection{Equation of State (EOS) Simulations}

RK-Aspen (Redlich-Kwong-Aspen) equation of state is generally considered a suitable equation for hydrocarbon systems. When using the Aspen Plus package, RK-Aspen can not only deal with nonpolar systems \{like the widely used RKS-BM (Redlich-Kwong-Soave-Boston-Mathias) equation of state [30] \}, but can also be extended to polar-nonpolar systems. Details of the RK-Aspen model for EOS calculations used here are given below:

$$
\begin{gathered}
P=\frac{R T}{v_{m}-b}-\frac{a(T)}{v_{m}\left(v_{m}+b\right)} \\
\text { where } a=\sum_{i} \sum_{j} x_{i} x_{j} \sqrt{a_{i} a_{j}}\left(1-k_{a, i j}\right) \\
b=\sum_{i} \sum_{j} x_{i} x_{j} \frac{\left(b_{i}+b_{j}\right)}{2}\left(1-k_{b, i j}\right) \\
a_{i}=f c n\left(T, T_{c i}, P_{c i}, \omega_{i}, \eta_{i}\right) \\
b_{i}=f_{c n}\left(T_{c i}, P_{c i}\right) \\
k_{a, i j}=k_{a, i j}{ }^{0}+k_{a, i j}{ }^{1} \frac{T}{1000} \\
k_{b, i j}=k_{b, i j}{ }^{0}+k_{b, i j}{ }^{1} \frac{T}{1000}
\end{gathered}
$$

The Binary Interaction Parameter (BIP) $k_{i j}$ were allowed to vary in the fitting of the data. Using Equations (9-15), we were able to estimate the Henry's constant of $\mathrm{H}_{2}$ in the system for a range of temperatures and pressures.

\section{Results and discussion}

The first set of simulations was carried out to obtain $\mathrm{H}_{2}$ solubility in pure components of interest. Initially we used standard TraPPE parameters for hydrocarbons and hydrogen. 
These were used to predict the solubility of hydrogen, and if experimental data was available, binary cross interaction parameters were adjusted as needed. An important advantage of such an approach in molecular simulations is that the interaction parameters are not expected to be sensitive to temperature and pressure changes. This can therefore provide more reliable predictions than EOS for gas solubility at high temperatures and high pressures, if data at moderate conditions is available.

\subsection{Interaction parameters for hydrogen in pure components}

The first component studied using molecular simulations was to represent paraffins viz. squalane $\left(\mathrm{C}_{30} \mathrm{H}_{62}\right)$. In our studies we used the known density of squalane at $300 \mathrm{~K}$ of 0.804 $\mathrm{g} / \mathrm{cm}^{3}$ [31]. A typical density profile from our simulation is shown in Fig. 4. From the density profile, the overall simulated squalane density is $0.812 \mathrm{~g} / \mathrm{cm}^{3}$ which is close to the experimental value and served to validate the model used here for squalane.

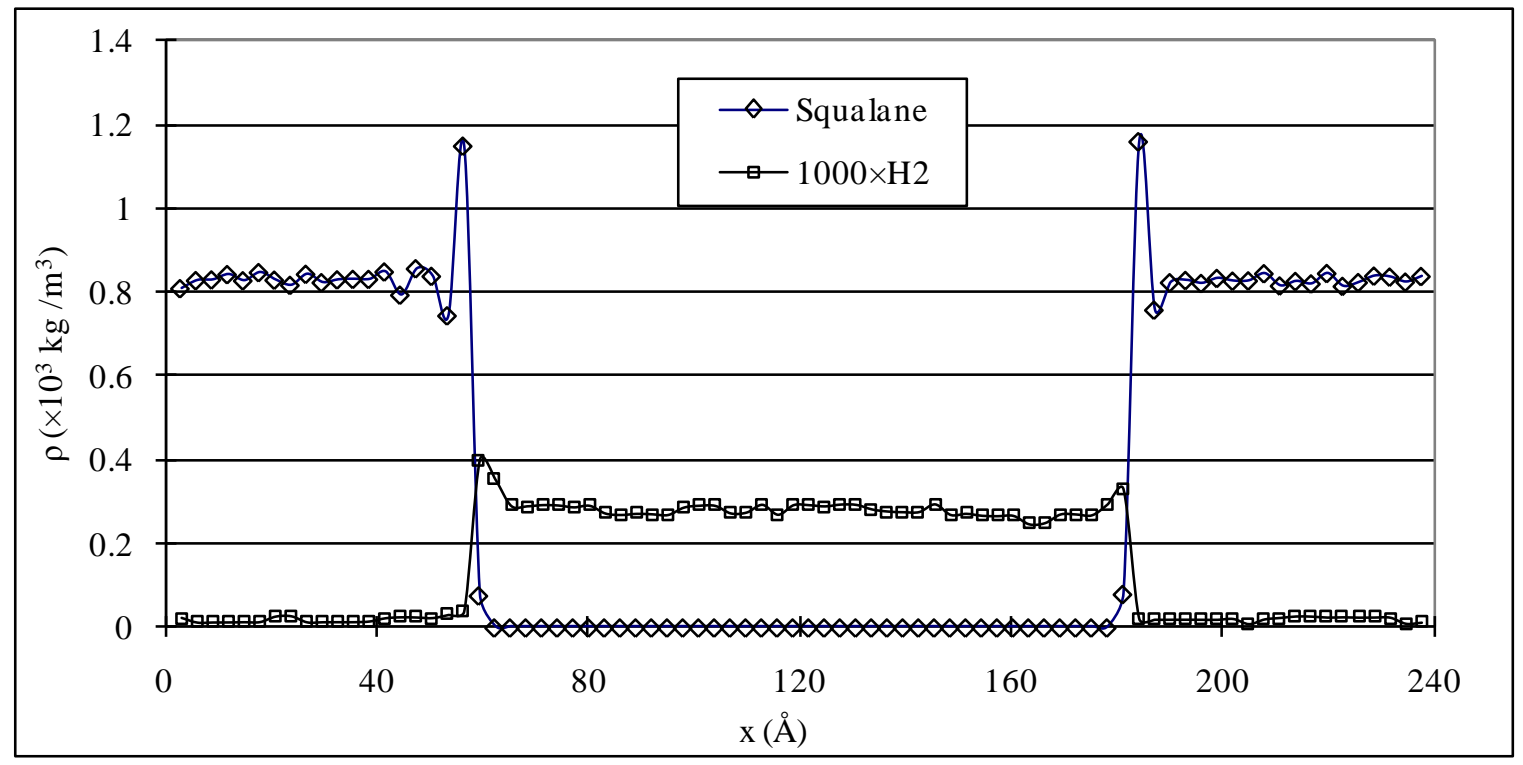

Figure 4 Density profiles of hydrogen and squalane in a typical simulation 
The interaction parameters between hydrogen and squalane were then adjusted to reproduce the experimental measurements at $300 \mathrm{~K}$. The values of the interaction parameters for squalane and other hydrocarbons studied are shown in Table 3.

Table 3 Interaction cross parameters used for hydrogen and hydrocarbons

\begin{tabular}{|c|c|c|c|c|}
\hline \multicolumn{2}{|c|}{ Category cross parameter with Hydrogen } & & $\eta$ & $\xi$ \\
\hline \multirow{3}{*}{ Paraffins } & \multirow{3}{*}{ Squalane $\left(\mathrm{C}_{30} \mathrm{H}_{62}\right)$} & $\mathrm{CH}_{3}$ (alkyl) & 0.85 & 1.00 \\
\hline & & $\mathrm{CH}_{2}$ (alkyl) & 0.85 & 1.00 \\
\hline & & $\mathrm{CH}$ (alkyl) & 0.85 & 1.00 \\
\hline \multirow{3}{*}{ Mononaphthene } & \multirow{3}{*}{$\begin{array}{l}\text { Methylcyclohexane } \\
\qquad\left(\mathrm{C}_{7} \mathrm{H}_{14}\right)\end{array}$} & $\mathrm{CH}_{3}$ (alkyl) & 0.85 & 1.00 \\
\hline & & $\mathrm{CH}_{2}$ (cyclic) & 0.90 & 1.00 \\
\hline & & $\mathrm{CH}$ (cyclic) & 0.90 & 1.00 \\
\hline \multirow{3}{*}{$\begin{array}{c}2+\text { ring } \\
\text { naphthenes }\end{array}$} & \multirow{3}{*}{$\begin{array}{l}\text { Dicyclohexylethane } \\
\qquad\left(\mathrm{C}_{14} \mathrm{H}_{26}\right)\end{array}$} & $\mathrm{CH}_{2}$ (alkyl) & 0.85 & 1.00 \\
\hline & & $\mathrm{CH}_{2}$ (cyclic) & 0.90 & 1.00 \\
\hline & & $\mathrm{CH}$ (cyclic) & 0.90 & 1.00 \\
\hline Monoaromatics & Benzene $\left(\mathrm{C}_{6} \mathrm{H}_{6}\right)$ & $\mathrm{CH}$ (aromatic) & 0.85 & 1.00 \\
\hline \multirow{2}{*}{ Diaromatics } & \multirow{2}{*}{$\begin{array}{l}\text { Naphthalene ( } \\
\left.\mathrm{C}_{10} \mathrm{H}_{8}\right)\end{array}$} & $\mathrm{CH}$ (aromatic) & 0.85 & 1.00 \\
\hline & & $\mathrm{C}$ (aromatic) & 0.85 & 1.00 \\
\hline \multirow{2}{*}{$4+$ ring aromatics } & \multirow{2}{*}{ Chrysene $\left(\mathrm{C}_{18} \mathrm{H}_{12}\right)$} & $\mathrm{CH}$ (aromatic) & 0.80 & 1.20 \\
\hline & & $\mathrm{C}$ (aromatic) & 0.80 & 1.20 \\
\hline
\end{tabular}

We then carried out MD studies for three sets of pressures which would lead to three different solubilites. The error bars shown were estimated from the fluctuations in the density profiles (see Fig. 4). These were then plotted as shown in Fig. 5. Henry's constant at $300 \mathrm{~K}$ was thus estimated as $\mathrm{H}_{12}=715 \pm 100$ atm by extrapolating to the limit $\mathrm{x}_{1} \rightarrow 0$ as required by Equation 5. The error bar reported here is based on error bars associated with the simulations results and the extrapolation of the simulation results to $x_{\mathrm{i}} \rightarrow 0$. The possibility of systematic errors also exists, but we attempted to minimize those by starting simulations at several different configurations and concentrations. The result obtained appear to be in good agreement with the experimental value of 726 atm [32]. 


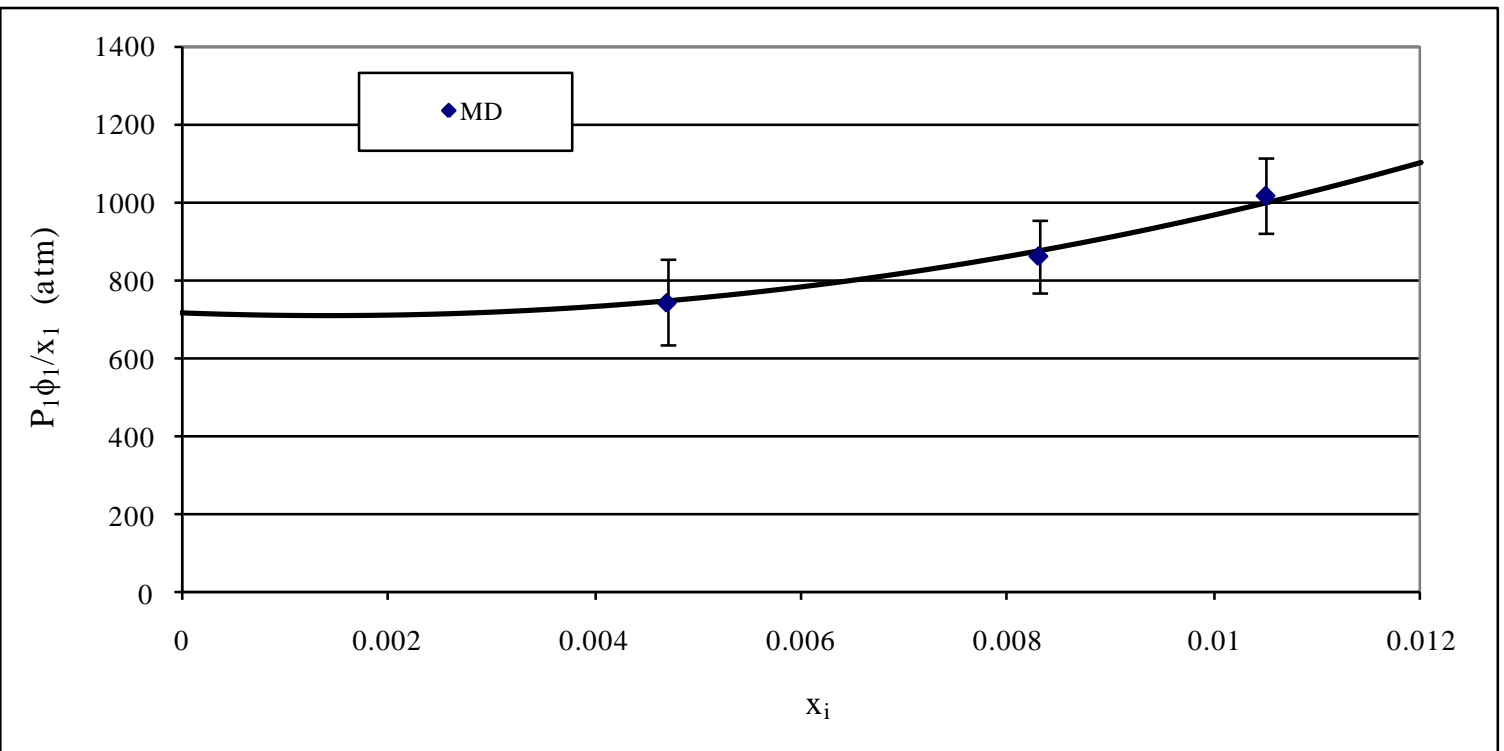

Figure 5 Pressure dependence of solubility of $\mathrm{H}_{2}$ in squalane, Henry's constant was obtained by extrapolating to $x_{i} \rightarrow 0$. The solid line is a polynomial fit of the data with a slope of 0 at $x=0$.

We also used this methodology to predict hydrogen solubility in other pure hydrocarbon components studied. The results are summarized in Table 4. They are also compared with any available experimental data (for experimental measurements the error is generally at least $10 \%$ ).

Table 4 Henry's Constant for pure components investigated

\begin{tabular}{|l|l|l|l|l|}
\hline \multirow{2}{*}{ Group } & $\begin{array}{l}\text { Representative } \\
\text { Components }\end{array}$ & $\begin{array}{l}\text { Simu. Henry's } \\
\text { Constant (atm) }\end{array}$ & $\begin{array}{l}\text { Expt. Henry's } \\
\text { Constant (atm) }\end{array}$ & Temperature (K) \\
\hline Paraffins & Squalane $\left(\mathrm{C}_{30} \mathrm{H}_{62}\right)$ & $715 \pm 92$ & $726[32]$ & 300 \\
\cline { 3 - 5 } Mononaphthene & $\begin{array}{l}\text { Methylcyclohexane } \\
\left(\mathrm{C}_{7} \mathrm{H}_{14}\right)\end{array}$ & $1100 \pm 137$ & $589[32]$ & 350 \\
\hline 2+ ring naphthenes & $\begin{array}{l}\text { Dicyclohexylethane } \\
\left(\mathrm{C}_{14} \mathrm{H}_{26}\right)\end{array}$ & $3575 \pm 492$ & $2510^{*}$ & 424 \\
\hline Monoaromatics & Benzene $\left(\mathrm{C}_{6} \mathrm{H}_{6}\right)$ & $2280 \pm 357$ & $2900[33]$ & 339 \\
\hline
\end{tabular}




\begin{tabular}{|l|l|l|l|l|}
\hline Diaromatics & Naphthalene $\left(\mathrm{C}_{10} \mathrm{H}_{8}\right)$ & $3180 \pm 442$ & $3100[33]$ & 423 \\
\hline 4+ ring aromatics & Chrysene $\left(\mathrm{C}_{18} \mathrm{H}_{12}\right)$ & $1725 \pm 238$ & $1470^{*}$ & 533 \\
\hline
\end{tabular}

* No experimental data available, estimated from RK-Aspen EOS by Aspen Plus simulation

We would like to note that pure organic solvents such as squalane $\left(\mathrm{C}_{30} \mathrm{H}_{62}\right)$, methylcyclohexane $\left(\mathrm{C}_{7} \mathrm{H}_{14}\right)$, benzene $\left(\mathrm{C}_{6} \mathrm{H}_{6}\right)$ (belonging to straight chain alkane, single ring naphthene, and single ring aromatics respectively), are relatively easier to simulate because of their well known molecular structures and lower densities and boiling points. Squalane has been simulated previously [16], with experimental $\mathrm{H}_{2}$ solubility data also available [32]. Methylcyclohexane is also a well understood single ring naphthene with a methyl branch which makes it structurally different from flexible normal alkanes. The ring structure makes the density profile often appears less uniform as a result of the many possible packing orientations of methylcyclohexane molecules. This is also the case for benzene molecules, which was used as a basic unit molecule to represent aromatics. Aromatics including Benzene, Naphthalene, and Chrysene were treated as rigid molecules [17].

For heavy hydrocarbons, high boiling points and high densities often make simulations problematic. In some cases the molecular structures of the components are still unknown. For example, one such heavy component, chrysene is a polycyclic aromatic hydrocarbon which consists of four fused benzene rings. It is a natural constituent of coal tar and often produced during combustion of petroleum products. The melting point of chrysene is $528-529 \mathrm{~K}$, with density of $1.27 \mathrm{~g} / \mathrm{cm}^{3}$, which is much higher than most organic 
liquids. In order to simulate such heavy components, we started the simulation at a low density configuration, equilibrated the system (the density profile was monitored to ensure equilibrium), then contracted the system size to increase the density. This procedure was repeated several times to finally reach the desired system density.

The results obtained from our simulations are shown in Table 4. It can be seen that overall our simulation results are in good agreement with available experimental results. In some cases like dicyclohexylethane and chrysene, where experimental values are not available, we believe our estimates to be reliable. The difficulty of performing experiments for these components is, in fact, the chief motive to use simulations. Molecular dynamics simulations also provide insight into the overall interaction between solutes and solvents. The cross interaction parameters between solutes and solvents with similar structural features seldom change. This permits potential parameters to be estimated for systems where no experimental data is available as well.

\subsection{Hydrogen Solubility in Heavy Hydrocarbons Mixtures}

In this section, we report results using two methods described previously, i.e., "Representative Molecules Approach" and "Pseudo Molecules Approach".

\subsubsection{Representative Molecules Approach}

The average carbon number of each component in a typical heavy hydrocarbon mixture is about 30. In our studies we used Benzene (C6), methylcyclohexane (C7), Dicyclohexylethane (C14), Naphthalene (C10), Chrysene (C18) and Squalane (C30). 
Although these representative components characterize the correct functional group, they do not represent the correct carbon numbers. To compensate for this discrepancy we investigated the model mixture at the experimentally measured density of $0.9253 \times 10^{3}$ $\mathrm{kg} / \mathrm{m}^{3}$ (rather than the estimated density of $0.506 \times 10^{3} \mathrm{~kg} / \mathrm{m}^{3}$ from the compositions of the model mixture in Table 2). A schematic of the system is shown in Figure 6. This configuration was again allowed to equilibrate, as described earlier. The liquid phase was equilibrated first, followed by the introduction of hydrogen molecules. The number of hydrogen molecules added to the central section corresponded to the desired hydrogen pressure.

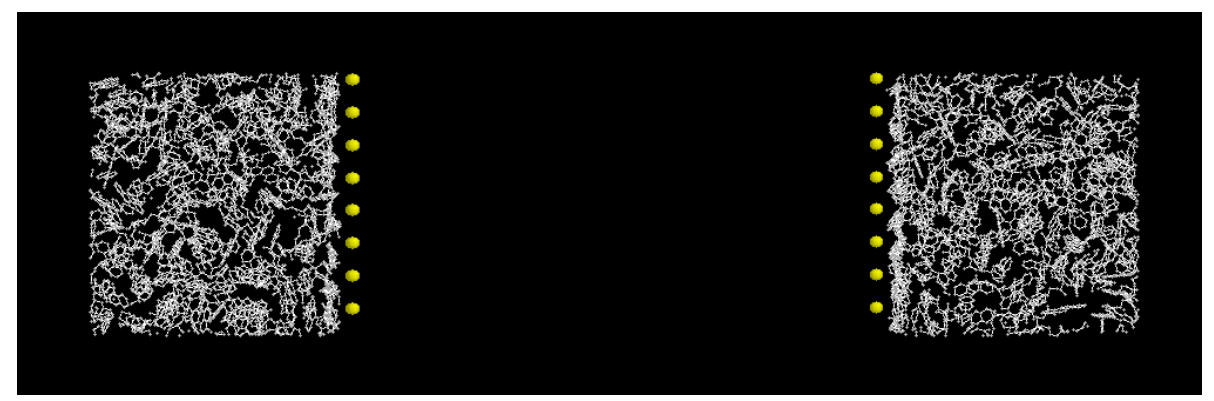

Figure 6 Snapshot of a typical hydrocarbon mixture during a simulation. The dynamic voids observed are formed and filled up during the simulation.

A typical density profile for such a system is shown in Figure 7. 


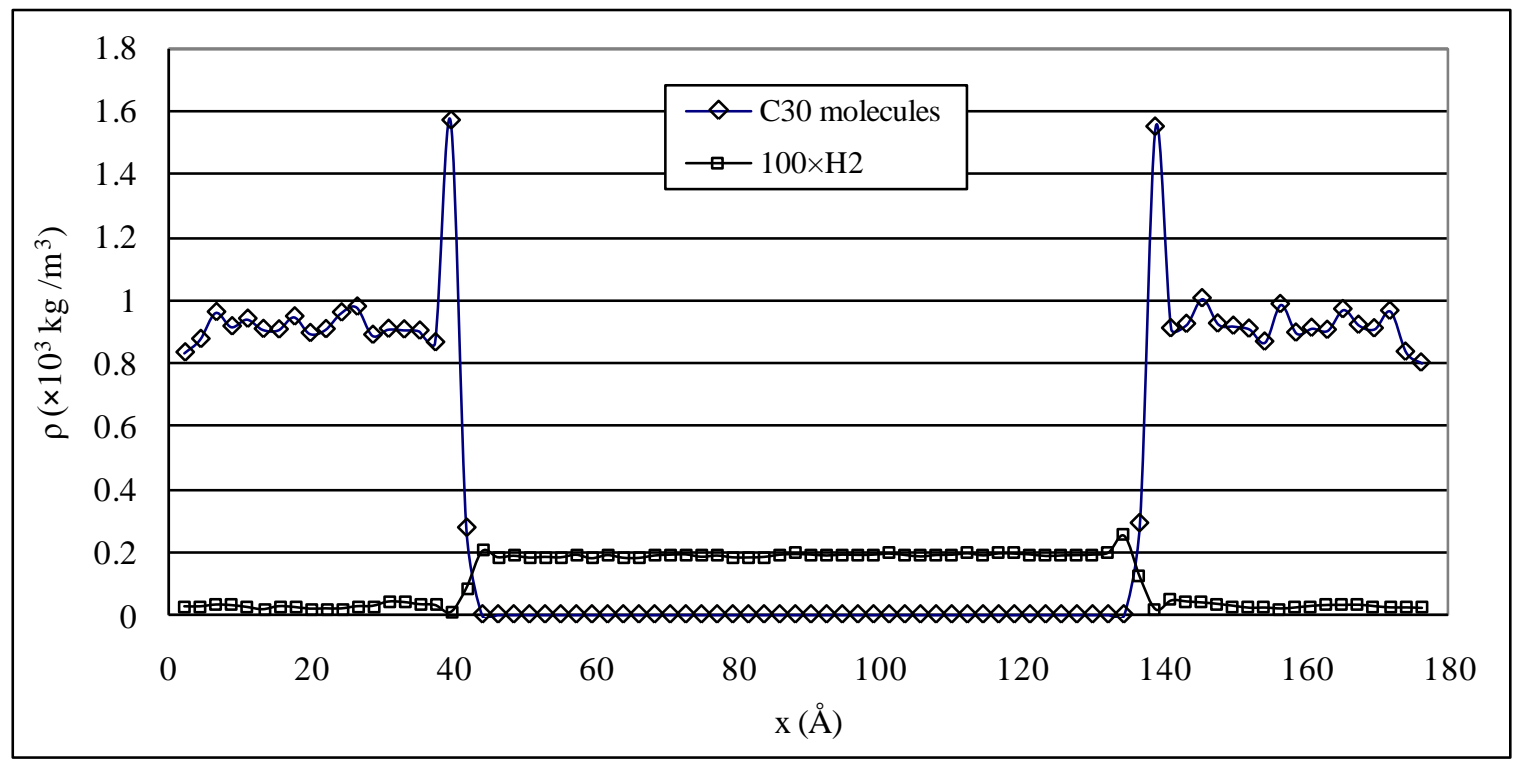

Figure 7 Density profiles of C30 and hydrogen molecules in a simulation

In the simulation, we inserted $80,120,160 \mathrm{H}_{2}$ molecules to the gas compartment, then estimated the $\frac{P_{1} \phi_{1}}{x_{1}}$. At $353 \mathrm{~K}$, the calculated second virial coefficient $\mathrm{B}$ is $15.415 \times 10^{-6}$ $\mathrm{m}^{3} / \mathrm{mol}$. To obtain Henry's constant, we extrapolated the curve to $x_{1} \rightarrow 0$. The estimated value was found to be $880 \pm 110 \mathrm{~atm}$. This value of Henry's constant can then be used to estimate the solubility of hydrogen in a mixture. For example this value of Henry's constant would correspond to a hydrogen mole fraction of 0.07 at a $\mathrm{P}=81.6 \mathrm{~atm}$. 


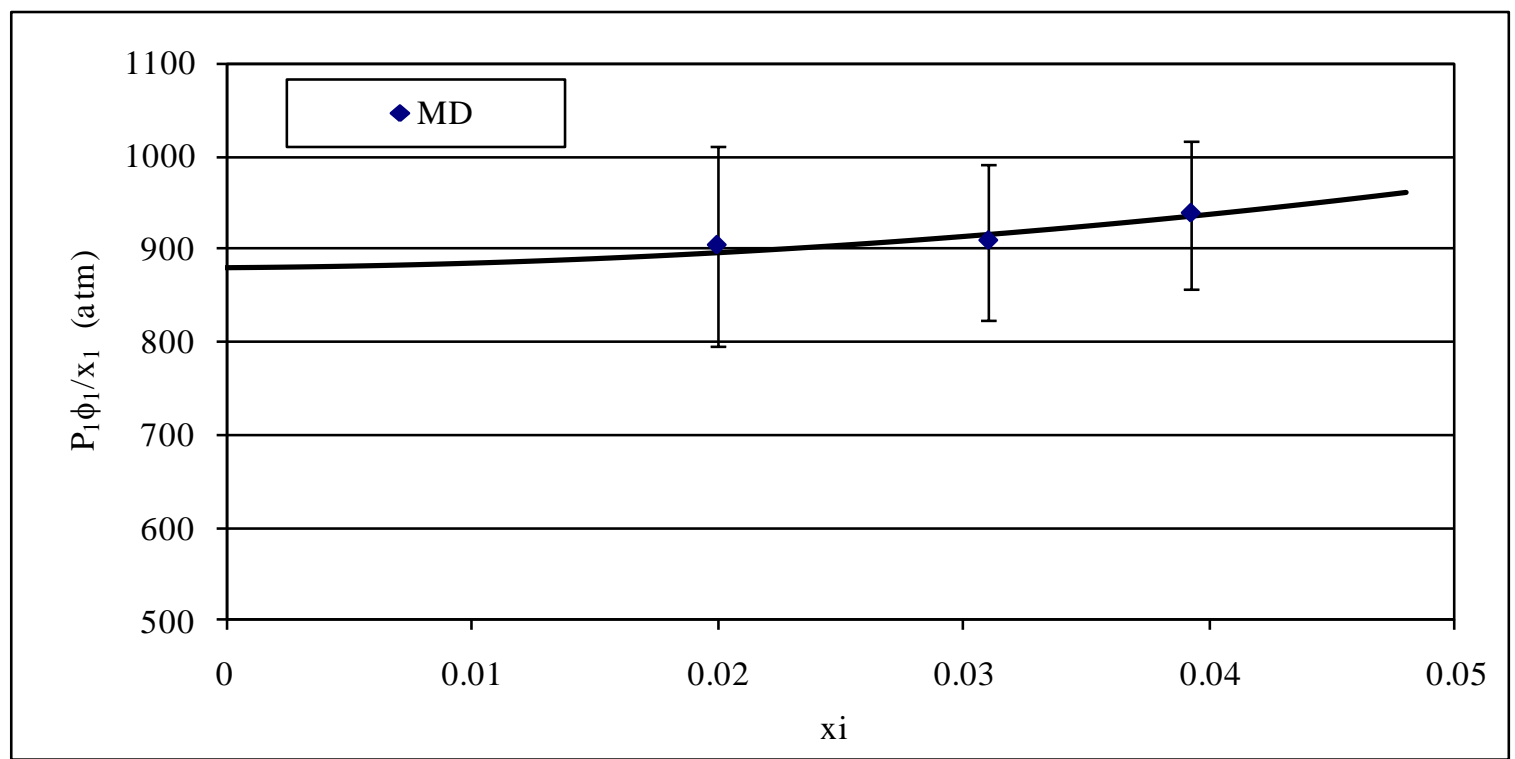

Figure 8 Henry's constant for a typical heavy hydrocarbon mixture (see Table 2), Henry's constant was obtained by extrapolating the polynomial fit (solid line) to $x_{i} \rightarrow 0$

\subsubsection{Pseudo Molecules Approach}

Here we used pseudo C30 molecules for each category (see Figure 2). These components were then included in the proportions representing a typical heavy hydrocarbon mixture shown in Table 2. In this case as we did previously, we used the experimental density of the heavy hydrocarbon mixture. We also used the methodology described earlier in section 4.1, for components with high densities and boiling point. As before, we added hydrogen to the system once the liquid phase had equilibrated. Density profiles obtained were similar to those shown in Figures 4 and 7. Once again by extrapolating the solubility results to $x \rightarrow 0$, we estimated Henry's constant to be $755 \pm 100$ atm. This agreed well with our previous estimate of $880 \pm 110$ from the "Representative Molecule Approach", considering the error bars in these estimates.

\subsection{Equation of State (EOS) Simulations}


We defined an ASPEN pseudo component with a density and average boiling point of the typical hydrocarbon mixture shown in Table 2, and then predicted the solubility of hydrogen in such a component. The results are shown in Figure 9.

We then adjusted the interaction parameters $\left(\mathrm{k}_{\mathrm{a}, \mathrm{ij}}{ }^{0}\right.$ and $\mathrm{k}_{\mathrm{b}, \mathrm{ij}}{ }^{0}$ in eqns. 13 and 14$)$ between hydrogen and the pseudo component to improve agreement between the ASPEN predictions and our molecular simulation results. The fitted binary parameters $\mathrm{k}_{\mathrm{a}, \mathrm{ij}}{ }^{0}$ and $\mathrm{k}_{\mathrm{b}, \mathrm{ij}}{ }^{0}$ were found to be -0.15 and 0.023 respectively. Figure 9 also shows the temperature dependence for both set of parameters (default and adjusted) using ASPEN for the weight fraction of hydrogen dissolved the heavy hydrocarbon oil. Figure 10 shows similar results for the pressure dependence of solubility from ASPEN. The difference between the results from the adjusted and default ASPEN parameters vary up to $40 \%$ (depending on the eqn. of state used in ASPEN). We have reported the results in mass fractions rather than mole fractions, since ASPEN does not define a molecular weight for the pseudo component representing the heavy oil.

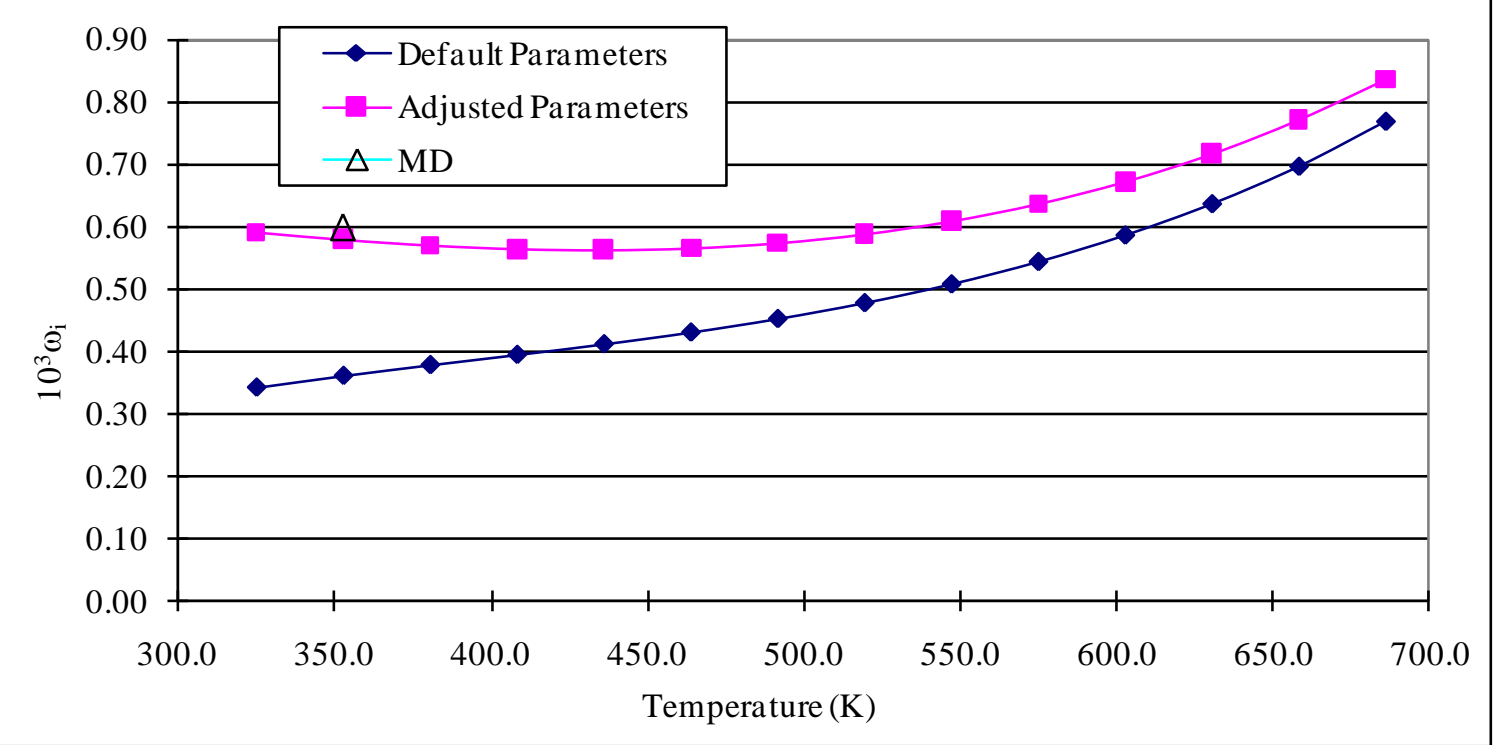


Figure 9 Temperature dependence of hydrogen solubility using ASPEN and MD. The solid line is to guide the eye

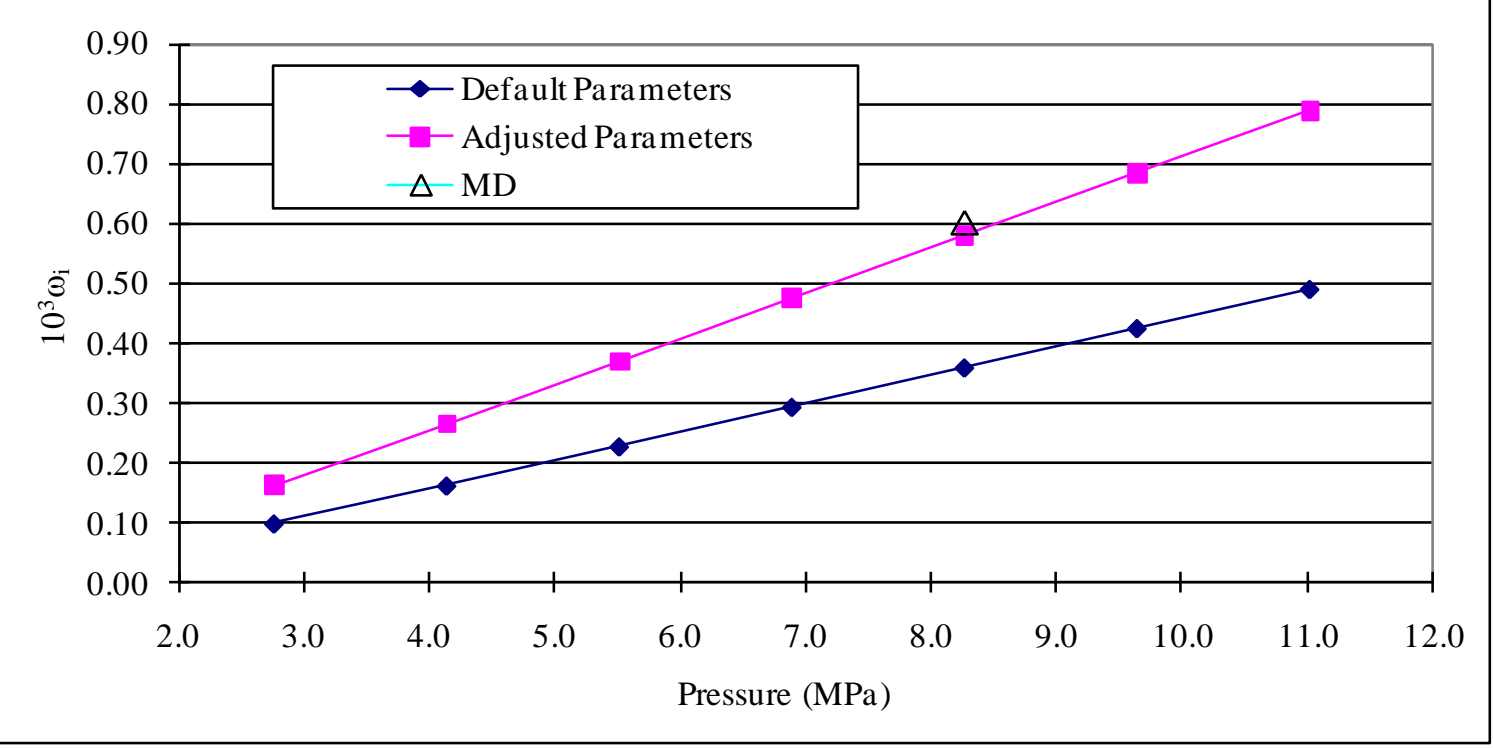

Figure 10 Pressure dependence of hydrogen solubility using ASPEN and MD.

\section{Conclusions}

We have used molecular simulations to study hydrogen solubility in heavy hydrocarbon systems using two different methods for representing heavy hydrocarbons, viz. (i) Functional group components; (ii) Pseudo components. We have shown that the combination of MD simulations with the simpler EOS techniques can provide a rapid scheme for predicting hydrogen solubility in heavy oils accurately. The EOS method is fast and easy to use, but not accurate especially at high temperatures and pressures, since EOS parameters are often state dependent. On the other hand, the MD simulations provide more accurate predictions at such conditions, but are more difficult to implement and time consuming. A combination of these two techniques, as described here leads to a useful practical method. 


\section{Acknowledgements}

This work was funded by the National Science Foundation (CBET 0314203) and UOP LLC.

\section{REFERENCES}

1. G. L. POLLACK, Science, 251(1991) 1323-1330.

2. A. Ghosh, W. G. Chapman, R. N. French, Fluid Phase Equilib., 209(2003) 229-243.

3. S. Gupta, J. D. Olson, Ind. Eng. Chem. Res., 42(2003) 6359-6374.

4. M. P. Allen, D. J. Tildesley, Computer Simulation of Liquids, Oxford University Press, Oxford, 1989.

5. K. E. Schmidt, D. M. Ceperley, The Monte Carlo Method in Condensed Matter Physics, Topics in Applied Physics, Vol.71, Springer, Berlin, 1992, pp. 205-248.

6. D. K. Remler, P. A. Madden, Mol. Phys., 70(1990) 921-966.

7. M. E. Tuckerman, M. Parrinello, J. Chem. Phys., 101(1994) 1302-1315.

8. H. Yuan, S. Murad, C. J. Jameson, J. D. Olson, J. Phys. Chem. C, 111(2007) 15771-15783.

9. H. Yuan, C. J. Jameson, S. K. Gupta, J. D. Olson, S. Murad, Fluid Phase Equilib., 269(2008) 73-79.

10. M. Krishnamurthy, S. Murad, J. D. Olson, Mol. Simul., 32(2006) 11 - 16.

11. R. Battino, IUPAC Solubility Data Series. Vol. 7, Pergamon, Oxford, 1981.

12. M.G. Ahunbay, S. Kranias, V. Lachet, P. Ungerer, Fluid Phase Equilib., 228-229(2005) 311-319.

13. P. Ungerer, V. Lachet, B. Tavitian, Oil \& Gas Science and Technology - Rev. IFP, 61(2006) 387-403.

14. S. Murad, S. Gupta, Fluid Phase Equilib., 187-188(2001) 29-37.

15. M. G. Martin, J. I. Siepmann, J. Phys. Chem. B, 103(1999) 4508-4517.

16. N. D. Zhuravlev, J. I. Siepmann, Fluid Phase Equilib., 134(1997) 55-61.

17. C. D. Wick, J. I. Siepmann, W. L. Klotz, M. R. Schure, J. Chromatogr. A, 954(2002) 181-190.

18. J. M. Stubbs, D. D. Drake-Wilhelm, J.I. Siepmann, J. Phys. Chem. B, 109(2005) 19885-19892. 
19. J. S. Lee, C. D. Wick, J. M. Stubbs, J. I. Siepmann, Mol. Phys., 103(2005) 99-104.

20. J. O. Hirschfelder, C. F. Curtiss, R. B. Bird, Molecular Theory of Gases and Liquids, John Wiley and Sons, New York, 1954.

21. C. D. Wick, M. G. Martin, J. I. Siepmann, M. R. Schure, Int. J. Thermophys., 22(2001) 111-122.

22. Z. Chen, F.A. Escobedo, J. Chem. Phys., 113(2000) 11382-11392.

23. T. M. Reed and K. E. Gubbins, Applied Statistical Mechanics, McGraw Hill, New York ,1973.

24. J. Fu, S. Kim, R. Rodger, C. L. Hendrickson, A. G. Marshall, Energy and Fuels, 20 (2006) 661-667

25. K. H. Altgelt, M. M. Boduszynski,Composition and analysis of heavy petroleum fractions, Marcel Dekker, New York, 1994.

26. S. J. Plimpton, J. Comput. Phys., 117(1995) 1-19 http://lammps.sandia.gov.

27. L. Verlet, Phys. Rev., 159(1967) 98.

28. W. A. Gerth, Arch. Biochem. Biophys., 241(1985) 187-199.

29. B. E. Poling, J. M. Prausnitz, J. P. O'Connell, The properties of gases and liquids. 5th ed. , McGraw-Hill, New York, 2004.

30. E. C. Carson, Chem. Eng. Progr., 10 (1996) 35-46.

31. O. Fandino, A. S. Pensado, L. Lugo, M. J. P. Comunas, J. Fernandez, J. Chem. Eng. Data, 50(2005) 939-946.

32. C. C. I. Chappelow, J. M. Prausnitz, AIChE J., 20(1974) 1097-1104.

33. N. Ferrando, P. Ungerer, Fluid Phase Equilib., 254(2007) 211-223. 